\title{
A ARte de FAzer Sapatos: Modos de FAZER E de APResentar NA INDÚSTRIA DE CALÇADO PORTUGUESA
}

Mariana Silva

Universidade Nova de Lisboa, Portugal

\begin{abstract}
Como modo de sobrevivência e adaptação às dinâmicas de produção e de mercado à escala global, a indústria de calçado portuguesa tem levado a cabo uma reestruturação produtiva e de negócio, com aposta no design e na modernização tecnológica, mas também na recuperação de modelos de produção artesanal. A partir de uma etnografia numa fábrica de calçado em Portugal, este artigo pretende tomar em atenção o quotidiano fabril de centros tradicionais de produção industrial, que em resposta a dinâmicas de mercado que procuram ancorar no passado artesanal a abertura no presente para novos modelos económicos, vivem o seu dia-a-dia no equilíbrio entre a recuperação de modos de fazer artesanais e a sua exibição. No cruzamento entre discursos de marketing e práticas de produção, procura-se a mobilização e a negociação de fronteiras entre conceitos como património e economia e, saberes-fazer artesanais e produção industrial.

Palavras-chave: indústria, calçado, património, saber-fazer, Portugal
\end{abstract}

Certos dias, entro no piso da produção e, num lugar discreto, sento-me simplesmente a observar. ${ }^{1}$ Grande parte dos trabalhadores estão no seu lugar, circunscritos a poucos metros quadrados, entre máquinas, mesas de trabalho, ferramentas e sapatos em construção. Sentados ou em pé, poucos são os que circulam. A circulação está quase exclusivamente reservada aos responsáveis pelas secções e aos que fazem chegar a "obra" ${ }^{2}$ entre uma secção e outra. Tudo parece no lugar e tempo certo do imaginário comum do que é uma área de produção industrial. Mas um olhar mais próximo é revelador de fugas em fronteiras cada vez menos rígidas. No "carros-

$1 \quad$ Faculdade de Ciências Sociais e Humanas da (NOVA FCSH); ISCTE - Instituto Universitário de Lisboa (ISCTE-IUL); Centro em Rede de Investigação em Antropologia (CRIA). Agradeço os comentários e sugestões de João Leal e dos editores e pareceristas da revista Cadernos de Arte e Antropologia a uma versão preliminar deste artigo. Contato: marianasilva413@gmail.com.

2 Termo emic usado para designar os sapatos durante o processo de produção, antes de estarem acabados. 
sel" ${ }^{3}$ multiplicam-se os pares de sapatos de modelos diferentes em volumes variados, intercalados com pares únicos e personalizados. $\mathrm{Na}$ secção da costura, em vez de cada gaspeadeira ${ }^{4}$ estar a cumprir uma tarefa única repetidamente, trabalham duas a duas em conjunto na execução de toda a componente de costura do sapato. Ao lado da máquina de fechar sapatos está o pequeno banco tradicional de madeira dos sapateiros, para estes se sentarem na hora de fechar sapatos à mão. $\mathrm{O}$ som de uma máquina pode ser muitas vezes substituído pelo som do martelar à mão, porque o tempo de afinar a máquina a cada novo par não compensa. Se no passado podiam passar dias e dias a produzir o mesmo modelo, muitas vezes repetido na coleção do ano seguinte, hoje, em cada novo dia, os pares de sapatos que lhes passam pelas mãos podem mesmo chegar a ser todos diferentes. O cenário que aqui vos traço é o de uma fábrica de calçado de média dimensão localizada em São João da Madeira, uma pequena cidade portuguesa situada numa das principais regiões produtoras de calçado do país. Com mais de sete décadas de história, sempre sob a alçada da mesma família e com várias gerações de trabalhadores do calçado, os objetos e as práticas que aqui circulam são representativos do caráter híbrido do que pode ser hoje uma produção industrial.

\section{INTRODUÇÃO}

Em O novo espírito do capitalismo, Luc Boltanski e Ève Chiapello (2009 [1999]) retratam o fenómeno contemporâneo de mercantilização da cultura como uma das principais formas de conciliar a busca da autenticidade com a exigência de acumulação do capitalismo. Ou seja, a mercantilização de bens e práticas que até aí tinham ficado fora da esfera do mercado - razão pela qual também eram considerados autênticos - torna-se um dos processos através do qual o capitalismo integra nos dispositivos que lhe são próprios a crítica à inautenticidade da massificação e uniformização da sociedade industrial. Contudo, como defendem os mesmos autores, a crítica à produção em massa conduziu a uma resposta de endogeneização da reivindicação da autenticidade também pelos mecanismos tradicionais do capitalismo industrial. Em oposição aos produtos padronizados do fordismo, começaram a ser introduzidas modificações na produção industrial, para que esta pudesse oferecer bens mais diferenciados e com referências extraídas de "um estado anterior das relações comerciais, em que o comprador estava diretamente diante de um artesão, que era ao mesmo tempo fabricante e comerciante, numa praça de mercado". (Boltanski \& Chiapello 2009 [1999]: 449)

Numa tentativa mais recente de redefinição crítica do capitalismo contemporâneo, a économie de l'enrichissement é a nova proposta de Luc Boltanski agora com Arnaud Esquerre (2017). Com a confiança num depósito que não é outro senão o passado, esta é uma economia que mais do que produzir coisas novas, depende do enrichissement das coisas que já existem. Dentro deste universo - que vai desde o património, ao mercado da arte e do luxo - estão os objetos que encontram na fabricação artesanal, habitualmente associada a marcadores identitários garantes de autenticidade, a ancoragem no passado para formulações contemporâneas.

3 Termo emic usado para designar a estrutura metálica que acompanha a linha de produção desde a secção da montagem até ao acabamento.

4 Gaspeadeira é a designação profissional para as costureiras que realizam a componente de costura de um sapato. 
Deste modo, ideias de salvaguarda de modos de produção artesanal ao passarem a integrar processos de construção do valor de troca das mercadorias, mostram em que medida a capacidade adaptativa do capitalismo soube usar o interesse pelo passado visto como reserva de autenticidade e o sentimento de crise e de risco de desaparecimento, subjacentes aos empreendimentos patrimoniais, passando a circular também dentro daquilo que se pode designar como endangerment sensibility. (Vidal \& Dias 2016) Como Rodney Harrison (2016) defende, muitas vezes as ideias que circulam dentro do património oficial acabam por influenciar aquilo que as pessoas acreditam que é o seu património, passando a circular no domínio do património não-oficial. Isso é particularmente visível com o desempenho da categoria de Património Cultural Imaterial (PCI) da UNESCO na esfera pública, ${ }^{5}$ que tem facilitado a expansão da endangerment sensibility para fora do património oficial, com a inclusão de novos objetos em risco, incorporando agentes culturais e as suas práticas.

No entanto, apesar do regime global do património iniciado pela UNESCO ter trazido alguma indefinição às hierarquias estéticas historicamente estabelecidas - entre as chamadas high art e vernacular arts -, certo é que ao nível das elites, o gosto pelo artesanal e tradicional tem já uma espessura histórica que vem do século XIX. Tal contribuiu, não só, para a fundação de museus e disciplinas académicas preocupadas com a old way of life, imbricadas com regimes anteriores de proteção cultural, (Bendix 2015) mas também, para a emergência do mercado do luxo, pela capacidade de personalização e singularidade que o artesanal é capaz. (Lipovetsky 2012 [2003]) Aqui é importante aquilo que Pierre Bourdieu (2006 [1979]) demonstrou, isto é, o entendimento das práticas de consumo associadas a manifestações de gosto como estratégias de afirmação, reprodução e mobilidade social, onde os objetos de consumo são usados para materializar estratégias de distinção e identidade social.

Mas efetivamente, em tempos de uma nova economia do capitalismo, as transformações observáveis na esfera da oferta não deixam também de ser fruto de metamorfoses que radicam do consumo e das suas categorias de gosto. Como trata Gilles Lipovetsky (2012 [2003]), a consagração contemporânea deste universo de mercadorias - que o autor situa no quadro do comportamento do mercado do luxo - deve-se, por um lado, à crescente visibilidade social do universo do luxo, consequência do seu compromisso com os princípios da democratização de massas, mas também beneficia, por outro, desta nova valorização do "autêntico" e do "intemporal"- aspas do autor - associada à inflação patrimonial atual.

Ou seja, lado a lado com a centralidade concedida à criação e à diversificação - em lugar da produção e da repetição, corolário da mecanização industrial -, a reivindicação de uma identidade artesanal torna-se moeda de troca de uma modernidade cosmopolita, dentro daquilo que Gilles Lipovetsky e Jean Serroy (2013) chamam de regime estético do capitalismo. Mais do que a razão da qualidade estética das suas mercadorias, o foco encontra-se nos processos e nas estratégias que emprega de maneira estrutural na conquista dos mercados. Diferentemente da regulação fordiana anterior, o complexo económico-estético é menos centrado na produção em massa apenas pelo menor custo, do que nas estratégias de diferenciação simbólica de produtos e serviços, com aposta nas dimensões imateriais do consumo.

5 Com influência da tradição folclorista, as "técnicas artesanais tradicionais" são um dos domínios do PCI. (UNESCO 2003, I.Artigo 2०.2) 
Com a tónica numa lógica de mercado, o desenvolvimento desta nova economia do imaterial assenta também no desenvolvimento de estratégias de marketing, capazes de construir narrativas que transformem as dimensões imateriais em valor de negócio. De facto, uma das principais caraterísticas apontadas por vários autores a este regime económico é o seu foco no comércio. No caso da formulação de Luc Boltanski e Arnau Esquerre (2017) em Enrichissement. Une critique de la Marchandise, os autores acabam mesmo por observar que o lucro, mais do que vir da produção de novos bens pela exploração do trabalho, resulta agora da venda de mercadorias dotadas do tal capital simbólico do passado. No entanto, uma das críticas apontadas a estas formulações teóricas é a minimização da importância da produção industrial e das relações de produção, não só num enquadramento mais amplo da economia global, mas também no contexto específico em causa. (Ravelli 2017) Apesar da centralidade dos processos de mercantilização, os trabalhos de produção não deixaram de existir, inclusivamente de produção industrial.

Importa salientar, como já referido em cima, que parte deste movimento foi levado a cabo também por empresas com origem na era do capitalismo industrial. Ao debruçar-se sobre o campo do património industrial, Philip Xie (2015) refere como indústrias tradicionais em risco tiveram que reestruturar-se também enquanto "chic" heritage. Desta forma, os produtos industriais passaram a ser fabricados não apenas pela sua funcionalidade, mas também pela sua estética e exclusividade, pois a personalização e o trabalho manual têm a capacidade de criar um vínculo com o objeto, que o torna capaz de ser apreciado por mais tempo. Esta tendência encontra suporte na renovação do interesse por empresas locais e os seus artesãos, muitas vezes também enquanto forma de protesto contra as desigualdades da esfera da produção e do trabalho a nível global. Como continua o autor, deste modo o object industrializer e o heritage conservationist estão a começar a comunicar: "The net result of these developments is a soul-searching process in which former centers of industrial and artisanal creation seek out and celebrate their historical and cultural roots, and in so doing, exert influence on the future development of industrial heritage." (Xie 2015:26)

O presente artigo surge como parte de uma pesquisa que pretende analisar do ponto de vista antropológico processos contemporâneos de patrimonialização da indústria. ${ }^{6}$ Entre antigas fábricas que encerraram e ganharam nova vida enquanto museus ou objetos turísticos, ou resquícios de centros tradicionais de produção que passaram a circular no mercado da nostalgia, a pesquisa revelou o modo como a linguagem do património e o capital do passado também circulam em indústrias vistas como símbolos de modernidade. São agora setores da fileira industrial contemporânea, que procuram ancorar em ideias de preservação de modos de produção do passado, a abertura no presente para modelos económicos assentes na retórica da inovação, do design e da criatividade. No caso português, o setor do calçado surge como paradigmático deste movimento.

Tendo em conta o breve quadro teórico enunciado e a partir de uma etnografia na fábrica de calçado que introduzi nas linhas acima, neste artigo procuro partir dos lugares de produção como contributo para o entendimento deste novo modelo económico. Como impulso de sobrevivência e adaptação a dinâmicas de produção e de mercado à escala global, a indústria de calçado portuguesa tem levado a cabo uma reestruturação produtiva e de negócio, com aposta

6 O presente artigo apresenta os primeiros resultados de parte da minha investigação de doutoramento que está a ser levada a cabo no âmbito do Programa de Doutoramento FCT em Antropologia - Políticas e Imagens da Cultura e Museologia (NOVA FCSH/ISCTE-IUL), financiada pela FCT - Fundação para a Ciência e Tecnologia (PD/BD/113943/2015). 
no design e na modernização tecnológica, mas também na recuperação de modelos de produção artesanal. No cruzamento entre estratégias de marketing e práticas de produção, pretendo tomar em atenção o modo como este novo modelo económico conduz à mobilização e à negociação de fronteiras entre o campo do património e o da economia e, entre relações de produção industrial e princípios do trabalho artesanal.

\section{A INDÚSTRIA QUE SE QUER "SEXY": NOTAS SOBRE A INDÚSTRIA DE CALÇADO EM PORTUGAL}

A indústria de calçado é hoje muitas vezes exibida como uma das meninas bonitas da economia portuguesa. Num trabalho conjunto entre industriais e a associação empresarial do setor, ${ }^{7}$ amplamente alavancado pelos responsáveis pela política económica nacional, o calçado surge como símbolo de projeção do país - numa versão mais cosmopolita do DIY kit da nação (Lofgren 1989) -, assumindo já o papel de impulsionador de outros setores de atividade para além fronteiras. ${ }^{8}$

De um tempo em que muitos anunciaram o seu fim, o setor do calçado passou a viver tempos de crescimento, no quadro de modelos económicos assentes na aposta em estratégias de internacionalização, tendo em vista o aumento das exportações. Com taxas anuais de crescimento consecutivo desde o início da segunda década do século XXI, o setor tem uma taxa atual de exportação de 95\%, maioritariamente para países da União Europeia, mas com transações nos cinco continentes. ${ }^{9}$

No entanto, a apresentação do setor como um caso de sucesso no quadro da indústria transformadora portuguesa não é apenas de agora. Na primeira metade da década de 1990, a sua elevada vocação exportadora, com peso assinalável na totalidade das exportações nacionais, é já apontada como uma das principais características setoriais. (APICCAPS 1994) Com a vantagem competitiva de possuir uma mão-de-obra muito mais barata em comparação à restante Europa industrial, o setor levou a cabo uma tentativa de modernização, através de investimento no desenvolvimento tecnológico de um tecido produtivo até aí essencialmente artesanal e domiciliário. Com efeito, consolidou-se através da produção de grandes séries subcontratadas aos fabricantes portugueses por compradores estrangeiros em regime de private label, ${ }^{10}$ mas também através da instalação de unidades produtivas estrangeiras em território nacional.

7 A Associação Portuguesa dos Industriais de Calçado, Componentes, Artigos de Pele e seus Sucedâneos (APICCAPS) foi fundada em 1975 e tem vindo assumir a ação de um agente coletivo, com contributos para a análise e resolução de problemas estruturais.

8 A mais recente aposta de mercado da indústria de calçado portuguesa são os Estados Unidos da América. Numa aposta em ações conjuntas, em julho de 2018, o setor do calçado juntou-se ao vestuário e à joalharia na promoção da marca Portugal no mercado dos EUA.

9 O setor do calçado português, em 2010, exportou 69 milhões de pares num valor de 1297 milhões de euros. Após oito anos de crescimento consecutivos, em 2017, os valores cresceram para 83,3 milhões de pares, num total de 1965 milhões de euros. A uma taxa de crescimento de $20 \%$ ao nível do número de pares de sapatos vendidos para o mercado estrangeiro, corresponde uma taxa de crescimento de $52 \%$ do valor da faturação, o que salienta o peso da viragem para os mercados de gama alta na reconversão do setor. O mercado da União Europeia absorve $86 \%$ da taxa de exportações. (APICCAPS 2018)

10 O regime de private label consiste na produção das mercadorias por uma empresa para serem comercializadas sob a marca de outra empresa. 
Com um modelo de negócio assente na produção em massa de baixo custo, o calçado tornou-se um pilar importante da economia portuguesa, até à grande crise que viveu na viragem para o século XXI. O fim das barreiras do comércio internacional e o surgimento de novas geografias de produção levaram ao declínio do modelo de negócio da subcontratação e das grandes séries, assente na competitividade com base nos custos. Assistiu-se ao encerramento de muitas fábricas, muitas das quais grandes empresas de capital estrangeiro, que acabaram por deslocalizar a sua atividade para países com menores custos de produção. Nesse momento, foi essencialmente ao seu sistema produtivo endógeno que a indústria portuguesa de calçado ficou reduzida, composta por empresas de pequena e média dimensão (PME's), com uma forte aglomeração geográfica, ${ }^{11}$ e com uma tradição familiar, quer ao nível da sua administração como também ao nível dos seus trabalhadores, com gerações e gerações de famílias associadas ao calçado.

E se num primeiro momento tudo isto foi apontado como a sua maior fragilidade, hoje afirma-se, em grande parte, como o responsável pelo seu relançamento: base produtiva consolidada, manutenção de métodos de fabrico artesanais conjugados com tecnologias mais avançadas, rapidez e flexibilidade de produção potenciadas nas unidades produtivas de menor dimensão. A isto junta-se a aposta no design e no calçado como objeto de moda, dentro de uma estratégia de renovação da imagem coletiva que afirma o calçado português como a "indústria mais sexy da Europa”. ${ }^{12}$

Cada vez mais concentrado no calçado de maior valor acrescentado, numa viragem para os consumidores considerados mais exigentes - habitualmente associados a classes sociais com elevado poder de compra,$-{ }^{13}$ a aposta passa pelo design e a modernização tecnológica com o advento da robotização, mas também pela recuperação de modelos de produção artesanal, aliados a estratégias daquilo que podemos chamar de uma patrimonialização comercial, suportada por dinâmicas de mercado que apostam no valor comercial da tradição e do artesanal. Em conjunto com a crescente componente de design e criação como traço de distinção, o calçado português quer ser também reconhecido pela sua excelência de produção e qualidade, reivindicando o saber-fazer bem como capital identitário de exceção:

(...) porque o património de "saber fazer" calçado de excelência que Portugal preservou confere legitimidade e autenticidade à sua oferta, constituindo um valioso ativo que deve ser valorizado. A vocação de "shoemakers" das marcas portuguesas constitui uma mais valia na capitalização de valores intangíveis e uma real alternativa para os consumidores que não se reveem na oferta de marcas de lifestyle generalistas. O desenvolvimento de soluções tecnológicas que permitam compatibilizar a eficiência económica com a nobreza da produção artesanal é uma via que importa explorar na afirmação dessa diferença. (APICCAPS 2013: 41)

Deste modo, ao lado de ideias e de chavões discursivos como qualidade, inovação, tecnologia e criatividade, surge associada a ideia de produção artesanal, não raras vezes na sua versão inglesa de craftsmanship. Os sapatos portugueses apresentam-se, por exemplo, como um produto de luxo porque são "executados pela inteligência das mãos". (Mendes 2018) Ao querer integrar

11 O setor do calçado em Portugal tem uma forte concentração geográfica, distribuído essencialmente em torno de dois centros: os concelhos de Felgueiras e Guimarães (Braga) e os concelhos de Santa Maria da Feira, Oliveira de Azeméis e São João da Madeira (Aveiro). Estes cinco concelhos juntos representam três quartos do setor em Portugal. (APICCAPS 2018)

12 Com a campanha Portuguese Shoes: The Sexiest Industry in Europe, lançada em 2011, o setor nacional ganhou em 2013 o Prémio Europeu de Promoção Empresarial, promovido pela Comissão Europeia, na categoria de apoio à internacionalização de empresas. A final foi disputada entre o calçado português e o champanha francês.

13 A seguir a Itália, o calçado português tem o segundo preço médio mais elevado do mundo, afirmando que "Portugal exporta calçado caro e quer exportar calçado ainda mais caro". (APICCAPS 2013: 34) 
modelos recentes de digitalização da economia e da indústria 4.0, verifica-se que a flexibilidade e a capacidade de atender ao detalhe de uma base produtiva que integra sistemas artesanais é essencial para cumprir o objetivo de um trabalho mais próximo dos clientes finais, com níveis mais elevados de customização de produto e desenvolvimento de serviços personalizados. ${ }^{14}$

\section{A FÁBRICA COM O CAPITAL DO PASSADO}

"Estamos quase a caminhar para algumas imperfeições do feito à mão começarem a ser toleradas", disse-me em conversa a única mulher que, como membro da terceira geração da família proprietária, integra os quadros superiores da fábrica de calçado que serve de fundo etnográfico a este artigo.

Fundada em 1942, a empresa, que se especializou em calçado masculino clássico, ${ }^{15}$ começou por produzir 10 pares de sapatos por dia. Hoje, com cerca de 70 trabalhadores, tem uma capacidade de produção diária que pode chegar aos 300 pares. Contudo, em tempos em que os desenvolvimentos tecnológicos daquela que já denominam como a $4^{\mathrm{a}}$ Revolução Industrial - a indústria 4.0 - seriam capazes de colocar a fábrica a produzir milhares de sapatos por dia, olhar para o seu volume de produção diário é um dado indicativo do modo como ela se situa no setor na atualidade:

(...) se eu tiver um robot que dá cola a imitar o movimento da mão, eu vou fazer muitos mais sapatos. Mas para já, no meu modelo de negócio, eu não estou preparada para estar a fazer mil sapatos por dia, porque eu não tenho a quem os vender. (...) Mas há espaço para a indústria 4.0, otimização logística, as relações com os clientes, (...). E isso é customer service e é mais a nossa onda. É um 4.0 amoroso, percebes? Fofinho. (...) É tecnológico mas é para melhorar as relações, para trabalhar o emocional, que no fim do dia é o que nós acreditamos que ainda nos faz vender. (Designer, membro da 3a geração da família proprietária, 2018)

Numa empresa que conta com quatro gerações, em que as últimas três são responsáveis em conjunto pela gestão atual, "há muito chão por onde caminhar e voltar", como afirma a designer. Não deixando de integrar a mudança de paradigma do setor, onde ao foco na produção se juntou o foco no marketing e na imagem, onde são agora os economistas, os marketeers e os designers que estão à frente das empresas, esta nova geração não deixa, no entanto, de seguir os passos anteriores de alguma prudência no que diz respeito ao entusiamo com as promessas da tecnologia e das suas inovações:

(...) uma fábrica robótica, que entra para aqui sai para acolá, não queremos. (...) A (x) também era um potentado nos anos 90 e ninguém tinha CAD's ou o que seja, no início dos anos 90, os gajos montes de CAD's, cortar a uma rapidez bruta e de repente falha-te este cliente, ai o que faço com isto tudo, o que faço com uma fábrica ultra tecnológica que... e nós sempre fomos os velhos do Restelo, que às vezes também trazemos estes exemplos... (Designer, membro da $3^{a}$ geração da família proprietária, 2018)

14 Está a decorrer o programa de financiamento FOOTure 4.0- Roteiro do Cluster do Calçado para a Economia Digital que prevê um investimento de 49 milhões de euros até 2020. Tem como objetivos melhorar significativamente a flexibilidade de produção, ao mesmo tempo que quer trabalhar para um maior envolvimento do cliente, níveis mais elevados de personalização do produto e o desenvolvimento de serviços personalizados. (APICCAPS 2018)

15 Especializada em calçado para o mercado masculino, a partir do início da segunda década do século XXI começou também a produzir calçado feminino. Ao nível da marca própria, mantendo a sua tradição de construção de sapatos masculinos, tem vindo a apostar em coleções para os dois mercados que defendem a quebra de convenções de género, sob o conceito agender. 
Mas, se por um lado, a experiência acumulada torna-se alavanca para a resolução de problemas diários de gestão e de produção, muitas vezes cíclicos, a inscrição numa continuidade temporal com o passado é hoje também chave para a recente reorientação da empresa. Associada a ideias de produções diversificadas e personalizadas, suportadas por saberes-fazer acumulados por gerações de antecessores, a empresa tem levado a cabo uma reestruturação de imagem e de modelo de negócio assente na inscrição do passado como capital de distinção. ${ }^{16}$ Deste modo, uma área produtiva com um parque de máquinas pouco automatizado e muito dependente da relação homem e máquina é hoje vista não como fragilidade, mas sim como traço de distinção revestido por ideias preservacionistas de saberes-fazer e conhecimentos produtivos.

Ao mesmo tempo, a persistência pela preservação e até mesmo recuperação de algumas técnicas de produção antigas, muitas delas de caráter artesanal com uma forte componente manual, surgem igualmente como resposta a movimentos do mercado definidos por determinadas categorias de gosto:

Os modelos clássicos saem mais rápido que os modelos desportivos que são mais simples. As pessoas, se calhar para investir, investem num sapato mais caro, uma sapatilha compram num outlet. E porque muita gente também está a procurar outra vez o back to the basics, a construção manual, o restaurar, o ir ao sapateiro ... se calhar isso é uma coisa que nós podíamos ter. (...) O sapateiro está a desaparecer, por isso recebemos na fábrica os sapatos. E nós fazemos isso informalmente, mas como fazemos isso muitas vezes se calhar é um sinal ... o facto de nós podermos receber os sapatos, restaurá-los e voltar a enviar ao cliente. O futuro vai andar à volta dos serviços que tu podes criar, os apêndices todos que tu podes criar e as necessidades que tu podes criar às pessoas, neste mundo mais de luxo, que não é luxo, mas é um segmento mais alto. (Designer, membro da $3^{a}$ geração da família proprietária, 2018)

Com o objetivo de possuírem uma estrutura capaz de responder às flutuações da economia global, à aposta na marca própria junta-se a produção para clientes em regime de private label. ${ }^{17}$ Ao querer seguir outros setores (alta costura, joalharia, etc.) para os quais a baixa produtividade e o alto custo de produção são mais uma vantagem que um problema, a vontade é a de reforçar a produção de calçado de alto valor acrescentado:

(...) porque, lá está, o futuro do private label se calhar é este. Porque nós cobramos na mesma o que achamos que devemos cobrar. Enquanto as grandes marcas internacionais deixam-te por 5 cêntimos. Aliás, nós trabalhamos com a (x), se nós para o ano, o mesmo modelo, tipo o porco ficou mais caro, porque as peles são como as ações, e nós temos que aumentar 10 cêntimos, eles vão fazer para outro sítio. Porque 10 cêntimos em 10 mil, ou 20 mil ou 30 mil. (...) E nós se calhar temos de nos virar mais para o private label de alto valor acrescentado. Par a par, o personalizado. (...) Vê-se que começa a ser mais tendência. Pessoas que não se importam de pagar o que for preciso, mas para fazer aquilo. Isso também poderá ser um caminho da (empresa). (Designer, membro da 3a geração da família proprietária, 2018)

Com movimentos cada vez mais céleres de transferência da produção para geografias onde a força de trabalho é ainda mais barata e com níveis de qualidade produtiva crescentes, a dificuldade em competir na equação qualidade, produtividade e custo é cada vez maior. A tendência poderá ser o investimento no crescimento global das classes com poder económico para suportar o valor de mercado dos argumentos de marketing, da apresentação e dos serviços associados,

16 Isso é visível, por exemplo, na sua atual marca própria lançada em 2017, que reivindica o regresso aos princípios fundadores sob o lema the new formal e convoca a data de fundação da fábrica para um dos seus segmentos. 17 Segundo a empresa, a conciliação entre produção de marca própria e produção em regime de private label para vários clientes deve-se a duas razões principais: não depender apenas de uma via de produção e não estar exclusivamente dependente de um único cliente. Dentro do private label têm clientes com encomendas de grandes séries, coleções de criadores de moda e de autor, clientes que encomendam pequenas coleções numeradas e um cliente de calçado customizado. 
mas também das propriedades substanciais que derivam dos modos de produção artesanal. Para além das dimensões imateriais, a produção poderá ser considerada como a manufatura do valor:

Por isso é que ou vais para sapatos injetados ou para coisas de alta rodagem e de muita quantidade ou ainda tens de reduzir mesmo aos primórdios da oficina. Podes fazer um sapato durante um dia e meio e vendê-lo por 5 mil euros no fim. Aumentas o valor do produto. (Designer, membro da $3^{a}$ geração da família proprietária, 2018)

E tal como confidenciou a designer - deixando revelar que esta é uma questão na qual o patronato instituído faz "ouvidos moucos" -, esta via poderá contribuir para a resolução daquele que é apontado como um dos problemas estruturais da indústria portuguesa de calçado: os baixos salários dos seus trabalhadores. A este tema voltarei mais à frente.

\section{A ARTE DE FAZER SAPATOS: O CORPO QUE DESENHA}

No primeiro dia de trabalho de campo dentro da fábrica, foi ao responsável geral da produção que atribuíram a tarefa de me receber. Com mais de 50 anos de trabalho na empresa, este sapateiro foi um dos principais responsáveis pela reintrodução e adaptação de processos artesanais ao modo de produção atual da fábrica, onde numa única linha de produção faz-se desde sapatos em série até sapatos personalizados. A um determinado momento da nossa conversa, perguntei se agora estavam a recuperar métodos de trabalho iguais aos que eram usados quando veio trabalhar para a fábrica. Respondeu-me de imediato que "não!" Que antes era tudo "à bruta" e que hoje é completamente diferente. Sendo verdade que se está a recuperar alguns dos processos artesanais, parece também que isso não significa necessariamente um regresso a um tempo passado: “(...) quando o sapato era todo feito à mão, as mãos dos sapateiros não eram mãos, eram cepos. A indústria era má. Mas era o que havia.” (Responsável Geral de Produção, 2018)

No trabalho de manufatura dos dias de hoje parece que são outras as qualidades que devem ser mobilizadas. "Não é qualquer um que o consegue fazer", afirmam os que fazem. Nem todos têm as habilidades necessárias, dizem. Gosto e paciência para a delicadeza dos gestos que os processos exigem, ao contrário da brutalidade do trabalho manual do passado e em contraste com a velocidade e a repetição do trabalho mecânico:

Nem toda a gente consegue fazer este trabalho. É preciso ter gosto em primeiro lugar. (...) O que se quer é que o cliente veja que foi um sapato feito um a um à mão. (...) Pega-se no sapato e vê-se que tem trabalho. E então quem percebe de sapatos ainda mais. (Responsável Geral de Produção, Sapateiro há 54 anos, 2018)

A pintura das patines, ${ }^{18}$ apresentada como uma das técnicas crème de la créme dos sapatos com componentes manufaturadas, foi recuperada por este sapateiro em resposta a um pedido de um cliente, que foi um dos impulsionadores de algumas das principais reincorporações de processos artesanais na cadeia de produção atual da fábrica. Este cliente é uma marca de calçado masculino, ícone da customização de produto na indústria de calçado portuguesa, com venda online de sapatos personalizáveis até aos mínimos detalhes, produzidos um a um nesta fábrica.

18 Técnica onde os sapatos feitos em pele branca são pintados um a um à mão, com pincel ou esponjas, para terem um acabamento manual. 
Mas a pintura das patines surge quase já no fim da linha de produção do sapato. Muito antes, ao lado das máquinas tecnologicamente avançadas de corte automático de peles, estão as mesas de corte manual, porque como me disse um cortador, mostrando-me a sua mão como a sua principal ferramenta: “há coisas que precisam ser feitas à mão. É preciso ter técnica!" Já na seç̧ão da costura, onde uma gaspeadeira de mão trabalha em conjunto com uma gaspeadeira de máquina, dizem-me que o trabalho de olhar para o desenho de um sapato e começar a dar-lhe forma, unindo um conjunto vário de pequenas peças, é a sua "arte". Ou seja, dentro do próprio grupo de trabalhadores, encontramos a mobilização de uma ideia de trabalho artesanal próxima do que aponta Richard Sennet (2008), onde este é visto como um impulso humano básico associado ao desejo de fazer um trabalho bem feito, que se centra na íntima conexão entre mão e pensamento, habilidade e imaginação, talento e motivação.

Ao mesmo tempo, por norma, à certeza do saber-fazer alia-se a rejeição da inovação da criação. Estes trabalhadores recusam o domínio da criação do sapato enquanto ideia intelectual e criativa: "a ideia não é minha". "Mas é das minhas mãos que eles nascem”, acrescentam. "Sou eu que olho para a pele e vejo qual o melhor sítio para cortar as peças." "Sou eu que olho para estas peças e descubro qual é a melhor maneira de as unir todas." E aqui encontra-se o que Tim Ingold (2002 [2000]) mostra, que um artesão "desenha" a peça no interior de uma relação direta do seu corpo com a matéria.

No contexto em estudo, é efetivamente a partir do domínio da técnica que se assiste à construção da identidade destas pessoas enquanto trabalhadores. Os mesmos autodenominam-se pela função que desempenham na cadeia produtiva e que corresponde aos seus conhecimentos técnicos: cortadores, gaspeadeiras, montadores, etc. No entanto, ao mesmo tempo que habitualmente não recorrem à categoria de artesão - mais mobilizada pelos discursos que vêm de cima e de fora -, também não se apresentam como operários fabris. Isto pode dever-se a dois motivos. Primeiro, pela forma como a história de vida de trabalho da maioria destas pessoas mais do que organizar-se entre fábricas de setores diferentes, dispôs-se exclusivamente dentro do setor do calçado, por vezes num equilíbrio entre o trabalho fabril e o trabalho ao domicilio, onde o domínio da técnica é o seu capital de negociação. Segundo, pelo facto de apesar de a indústria ser um fator estruturante no território onde se situa a fábrica em estudo, a consciência da classe trabalhadora e das suas potencialidades emancipatórias permaneceu vulnerável a constrangimentos e afinidades de produção e a lealdades e sociabilidades de um passado de cariz rural. (Estanque 1999)

Retomando Ingold (2002 [2000]), a organização do processo de trabalho na manufatura é uma organização ao mesmo tempo de corpos especializados e de mentes treinadas, e repousa no conhecimento técnico e nas habilidades possuídas pelos próprios trabalhadores. Suportandose do argumento de Marx sobre o modo como a mecanização transferiu a agência humana do centro para a periferia dos processos de produção, para pensar a agencialidade das máquinas, o autor retoma-nos a ideia que ao servir as máquinas os trabalhadores das fábricas sentem a sua subordinação ao capital de uma forma que o trabalhador do detalhe não sentia. Contudo, apesar da emergência do trabalho artesanal como recurso económico adicional na contemporaneidade, mostrando o modo como a capacidade adaptativa do capitalismo sabe usá-lo, como se mostrará a seguir, não se considera que a relocalização do humano no centro do trabalho produtivo tenha conduzido ao enfraquecimento das relações de produção capitalistas. 


\section{A ARTE DE FAZER SAPATOS: FRUSTRAÇÕES, ANSIEDADES E DORES DE CORPO}

A elevação da figura do trabalhador fabril à categoria de artesão é também utilizada enquanto argumento para a captação de mão-de-obra para a indústria de calçado. Numa tentativa de valorização profissional, os trabalhadores são colocados como os principais detentores e transmissores de um conjunto de conhecimentos e habilidades sem os quais não seria possível fazer este tipo de sapatos. Aqui vê-se o recurso à revalorização contemporânea do domínio das habilidades manuais e, consequentemente, do trabalho manual, também como resultado de uma determinada crítica de meios intelectuais e académicos ao consumo e à alienação do trabalho industrial. (Miller 2007)

Contudo, se para alguns destes trabalhadores esta recategorização é sinónimo de reconhecimento e de distinção, para muitos outros não é suficiente. Como fazer este trabalho de valorização num setor com uma má imagem social associada ao trabalho duro e à exploração? Trabalhar na produção de uma fábrica de calçado ainda é muitas vezes visto como o destino de quem não tem mais opções: "Quem quer vir trabalhar para o calçado? Isto não é futuro para ninguém!", respondem-me alguns trabalhadores, quando lhes pergunto porque há dificuldade em captar pessoas para o setor:

Acho que (o calçado) não é valorizado nem bem visto. Também é mal pago. (...) Eu acho muito injusto! $\mathrm{O}$ trabalho que fazemos é preciso saber e é desmotivante. (...) Os jovens até podem vir para aqui se não conseguirem mais nada, mas quando arranjarem outra coisa vão embora. (Gaspeadeira há 34 anos, 2018)

O calçado é muito sacrificado. Tantas horas aqui enfiadas para ganhar o ordenado mínimo. E o sapato está tão caro! Explica-me?! Alguma coisa não está certo. E o calçado está a dar muito e o sapateiro é o mais mal pago. (Gaspeadeira há 50 anos, 2018)

Conscientes do valor comercial das dezenas de pares de sapatos que produzem por dia e da relação desigual entre preço de venda e os seus salários, chegam-me a dizer: "Sabes quantos salários me passam pelas mãos todos os dias?”. Como afirma Filomena Silvano (s.d.), a posse e o entendimento (o saber) de um objeto e a sua integração num habitus faz com que a cada grupo social corresponda determinado tipo de objetos, significando a relação com os mesmos proximidades e distâncias sociais. Para estes trabalhadores, a gradação social em que estes objetos participam passa todos os dias pelas suas mãos: estes são os sapatos que sabem fazer, mas não são os sapatos que o seu poder económica lhes permite comprar. A amplitude desta distância torna-se ainda maior no caso das mulheres trabalhadores que, com uma menor tradição reivindicativa, vêem muitas vezes, tal como acontece nesta fábrica, o seu salário não ultrapassar o ordenado mínimo nacional, tal como estabelecido pelo contrato coletivo de trabalho.

Observações como estas são reflexo da frustração que sentem por considerarem que não são recompensados com um salário compatível com a responsabilidade e a qualidade que lhes é exigida, mas também com as dores de corpo causadas pelos processos que dependem quase exclusivamente dos seus gestos especializados. E este é também um reverso da recuperação de processos artesanais. Apesar do trabalho manual de hoje não ter a exigência física do passado, devido ao auxílio de processos mecânicos em determinadas etapas do processo produtivo, este não deixa de exigir a mobilização contínua de gestos finos e precisos, que contrastam com a velocidade de trabalho e com a maior leveza física das tecnologias contemporâneas, características que parecem atrair mais os jovens: 
Uma pessoa está sempre na mesma posição a fazer movimentos com o braço. Com o passar do tempo, sempre a martelar, sempre a martelar, uma pessoa até pode arranjar ruturas nos tendões. (Gaspeadeira há 54 anos, 2018)

Nasceram na era da tecnologia. Há mais interesse em ver, em saber como se faz do que em trabalhar. Pergunta-se: queres vir para aqui? “Ai não!”, respondem eles. (Cortador há 45 anos, 2018)

E aqui surge a questão da aprendizagem. É preciso tempo e treino para "aprender a arte", como os próprios trabalhadores afirmam. Efetivamente, treino e habilidade fazem parte da definição de um trabalho artesanal. (DeNicola \&Wilkinson-Weber 2016) E neste caso, apesar da aposta do setor na formação profissional, ${ }^{19}$ a fábrica continua a ser encarada, tanto pelos patrões como pelos trabalhadores, como o lugar principal - e mais eficaz - de aprendizagem. Contudo, o tempo necessário ao treino dentro da fábrica parece não se coadunar com os tempos atuais de uma organização industrial.

Muitos dos trabalhadores com quem conversei nesta fábrica, contaram-me como começaram a trabalhar, ainda crianças, mal acabavam a escolaridade obrigatória - variável consoante a idade do trabalhador -, muitas vezes devido às dificuldades económicas familiares que os impediam de continuar a estudar. Num sistema de mestre e aprendiz, começavam por executar pequenas tarefas ao mesmo tempo que observavam atentamente o seu mestre a executar processos mais complexos. A doença e a falta de um trabalhador eram muitas vezes a justificação para serem chamados para realizar funções que durante muito tempo tinham aprendido quase só através da observação de verem o mestre fazer. Mas havia tempo para aprender, dizem-me hoje. Como entravam muito jovens, a fábrica era como uma segunda escola. Hoje não há esse tempo:

Era uma senhora ali numa mesa, sempre com muita canalha à volta. Era como se fosse uma escola. (Gaspeadeira há 46 anos, 2018)

Eles só querem pessoas com experiência... e as pessoas estudam, estudam, mas não sabem fazer. E não há tempo para ensinar. (Mas foi assim que vocês aprenderam?) Pois, mas eram outros tempos ... (Gaspeadeira há 38 anos, 2018)

Em A Corrosão do Caráter: consequências pessoais do trabalho no novo capitalismo, Richard Sennett (1998) defende que uma das principais mudanças do capitalismo recente são as novas formas de organizar o tempo de trabalho. Com um nível de escolaridade maior - também devido ao aumento da escolaridade obrigatória -, os jovens trabalhadores entram mais tarde e com qualificações formais mais elevadas. Com um processo de aprendizagem muito mais solitário, rapidamente deverão estar a produzir como os mais velhos. Mas não há tempo para parar e ensinar. $\mathrm{O}$ ritmo de produção para dar resposta à velocidade das encomendas é muito maior. Não há tempo para ensinar e não há tempo para aprender. Têm de ser rápidos a aprender, porque quase de um dia para o outro, ficam responsáveis por executar um determinado conjunto de tarefas, do início ao fim, sozinhos. Por vezes, podem ter a ajuda dos colegas mais velhos que por iniciativa própria vão dando algum auxílio. Mas numa espécie de relação de solidariedade tal não deixa sempre de estar dependente da iniciativa individual e da qualidade das relações pessoais.

19 Desde 1965 que existe o Centro de Formação Profissional da Indústria de Calçado, atual Academia de Design e Calçado, com um polo em São João da Madeira. 
Contudo, à velocidade de aprendizagem sobrepõe-se outra dimensão do tempo que também importa atender. Num período de necessidade de renovação e crescimento da equipa de produção, exatamente pela dificuldade de atrair jovens para o setor, alguns dos novos trabalhadores desta fábrica não são jovens a iniciar o seu percurso profissional. Podem mesmo até ser pessoas com experiência no calçado - apesar de habitualmente mais treinadas em produções em série -, mas na sua maioria marcadas por situações de contratos temporários consecutivos, de salários em atraso e de desemprego. Ou seja, marcadas por aquilo que Sennett (1998) trata como o fim do tempo de trabalho a longo prazo, o que contribui para a corrosão dos princípios da confiança, da lealdade e do compromisso mútuo. Neste caso, à ansiedade da velocidade de aprendizagem junta-se a ansiedade da perda de confiança de quem encara que devido à sua idade esta poderá ser a sua "última oportunidade". Isto é, se no caso dos mais jovens a ausência de confiança que deriva do sistema de curto prazo pode, por vezes, conduzir também à falta de compromisso pela aprendizagem do trabalho bem feito, para estes trabalhadores mais velhos é a dedicação à superação das dificuldades de aprendizagem reveladora da sua vontade de compromisso.

Certo é que este sistema de aprendizagem e de treino solitário e o facto da recuperação de métodos de produção artesanais significar que cada trabalhador não tem apenas a seu cargo uma única tarefa repetida, mas sim um conjunto de processos que mobilizam uma rede mais complexa de habilidades e conhecimentos que têm de ser articulados, acarreta também um nível alto de ansiedade para estes trabalhadores. E não apenas aos trabalhadores com menos experiência, mas também àqueles que estavam habituados à realização de apenas uma tarefa repetida, segundo a tradicional divisão do trabalho industrial em série:

Só estou na máquina há quatro anos. Vim para aqui de um dia para o outro e ninguém me explicou nada e eu também não perguntei. E agora faço amostras. (...) Mas fico muito nervosa. É muita pressão. São muitas peças e é preciso olhar para o desenho e montar. E eles querem rápido e eu não consigo. (Gaspeadeira há 36 anos, 2018)

$\mathrm{Na}$ secção da costura, ter a cargo a feitura de amostras - pares de sapatos únicos representativos de um determinado modelo - é sinal, por um lado, do domínio de todas as etapas do trabalho de mão e de máquina e, por outro, do reconhecimento da qualidade e da perícia do trabalho da gaspeadeira pela entidade patronal. São os sapatos que representarão as coleções junto dos clientes e em feiras internacionais. A qualidade do seu fabrico poderá ser decisiva nas vendas dessa coleção. Logo, apesar de no caso da fábrica em estudo tal não ser sinónimo de uma distinção salarial - todas as gaspeadeiras, independentemente da categoria profissional e dos anos de experiência e de contrato de trabalho, ganham o salário mínimo nacional -, entre pares, é estruturante na criação e manutenção de hierarquias informais. E aqui o domínio da técnica, ou neste caso, do maior número de técnicas do processo produtivo, é muito importante.

Mas nesta passagem do trabalho em série para um tipo de trabalho mais personalizado e de detalhe, num equilíbrio entre o sentimento de ansiedade e de estímulo pelo trabalho contínuo de mobilização de conhecimentos vários e novas aprendizagens para a resolução de problemas diários que se multiplicam à razão da diversidade de produção, os trabalhadores que possuem um passado de trabalho ao domicílio parecem sentir-se muito mais confortáveis. A indústria de calçado portuguesa sempre se caraterizou, e continua a caraterizar-se, por uma intensa componente de trabalho ao domicílio de subcontratação. No caso da mão-de-obra feminina, muitas são as mulheres que, como modo de conciliar o apoio à família - tradicionalmente centrado na figura feminina - com a emancipação financeira concedida pelo trabalho, com a possibilidade - 
por aquisição ou por empréstimo - de terem uma máquina de gaspear em casa, organizaram a sua vida de trabalho entre o espaço da casa e o espaço da fábrica. Num equilíbrio entre a sua vida pessoal e as oscilações do setor, em tempos em que o trabalho subcontratado - quase em jeito de trabalho por conta própria - é profícuo, organizam os seus dias entre o papel de cuidadoras e o gaspear sapatos fora de horas. Em tempos em que a estabilidade de um salário certo ao fim do mês se torna premente, regressam à fábrica e ao seu toque diário da hora certa. Habituadas a costurar o sapato do início ao fim sozinhas, na tradição do trabalho oficinal, em períodos como os de hoje tornam-se trabalhadoras que quase qualquer fábrica quer ter a oportunidade de contratar.

A falta de trabalhadores qualificados na indústria de calçado é um tema que está na ordem do dia. Dentro e fora de portas. Anunciam-se campanhas de comunicação para tornar o setor atrativo para os jovens, ${ }^{20}$ ao mesmo tempo que nos corredores das fábricas se fala da dificuldade em encontrar "quem saiba fazer". Mas à boca pequena, quando se fala em dificuldades no recrutamento também se fala invariavelmente das condições de trabalho e dos baixos salários. Há quem diga - mesmo dentro do grupo dos trabalhadores - que apesar dos salários serem baixos é melhor receber um baixo salário do que estar desempregado, sem trabalho. Outros que entre o que se ganha a trabalhar e o subsídio de desemprego pouca é a diferença. E outros ainda que para a "mestria" necessária o salário é muito baixo. "Para ter mais gente no calçado precisas de pagar bem”, disse-me a designer da família proprietária da fábrica. Observou que não é uma questão para a qual as administrações das empresas estejam muito sensibilizadas - das gerações mais velhas às mais novas -, mas afirmou que tem a conviçção que a resolução da renovação dos quadros terá de passar por aí. Tanto mais quando se tratam de fábricas que querem apostar em modelos de produção artesanal. Para a designer, no caso da fábrica de família, considera que o caminho será a construção de duas linhas de produção, uma dedicada a produções em série e outra exclusivamente em regime de oficina artesanal:

Eu acho que agora se nós quiséssemos crescer em músculo para depois poder ter capital para investir nos nossos "meninos", ${ }^{21}$ isto cabia numa lógica de termos uma unidade especial de manufaturados, que era acompanhada por uma unidade mais tecnológica com outro tipo de produto para outras marcas. (Designer, membro da $3^{a}$ geração da família proprietária, 2018)

Aqui o que parece que se assiste é à contradição contemporânea entre o sistema de poder que se esconde na moderna forma de especialização flexível (Sennett 1998) e os fundamentos da produção artesanal, num contexto com hábitos e práticas enraizadas do sistema industrial fordista. À especialização flexível que serve este novo modelo económico, também ancorado na recuperação de modos de produção artesanal, exige-se que se coloque no mercado produtos variados cada vez mais rapidamente. Mas do mesmo modo que as técnicas artesanais são úteis na resposta à reivindicação de elevados níveis de diversificação e personalização, por outro lado, a rápida resposta não se coaduna com os seus princípios. Deste modo, a dimensão do tempo poderá ser aqui a chave. Aumentar tempos de produção. Aumentar tempos de aprendizagem. Aumentar o tempo para a criação de laços sociais de confiança e compromisso para com o trabalho bem feito. Aumentar o valor do produto pelo tempo do trabalho. E consequentemente aumentar salários.

20 A campanha Feeling Sexy: vem pertencer à indústria mais sexy da Europa é a campanha de angariação de jovens lançada pela APICCAPS em 2017.

21 Para a consolidação da marca própria, a empresa sente que neste momento seria importante a aposta nos meios de comercialização digitais - também pelo declínio das lojas físicas -, o que exige investimentos de capital muito elevados. 


\section{O DIA DE SUBIR A UMA PASSARELA: NOTAS FINAIS EM JEITO QUASE DE DESEJO}

Desde os primeiros dias de observação dentro da fábrica, quando ia ao encontro de um sapateiro, muitos começavam por apontar para um colega e dizer: "ai aquele é que é o artista!" Sempre para o mesmo colega. Desta forma, a primeira vez que conversei com aquele para quem apontavam, logo lhe perguntei a razão de tal forma de o apresentarem, ao que me respondeu: "Pois sou o único sapateiro aqui que sabe fazer tudo. Eu já fui a Londres e tudo, mostrar como se faz um sapato. E agora se calhar vou a Nova Iorque!"

Com a centralidade concedida aos modos de produção artesanal, convocados como modos tradicionais de produção mobilizados por novas modalidades de negócio e de consumo, os trabalhadores categorizados enquanto artesãos passaram a estar no centro das construções de marketing destes bens de consumo. De uma visualidade composta por imagens de mesas e ferramentas tradicionais e planos focados das mãos que constroem um sapato, a práticas discursivas marcadas por tendências preservacionistas que apelam a sentimentos de risco de desaparecimento, assiste-se também a uma relocalização e encenação do trabalho para fins de exibição, onde trabalhadores são colocados a realizar demonstrações em eventos promocionais, por exemplo. No entanto, pensar em quem é escolhido para se tornar objeto de exibição e nos palcos dessa mesma exibição, obriga a pensar novas questões sobre os modos de apresentar a arte de fazer sapatos. Com tal me interroguei quando ouvi o quase desejo com o qual termino este texto, em jeito de conclusão em aberto para reflexões futuras.

Depois de ouvir histórias de viagens nunca antes feitas e de entrevistas dadas à comunicação social, na seç̧ão da costura, sentada lado a lado com as gaspeadeiras, em conversas de registo quase confessional, o desabafo é outro. Ao conversar sobre se estas sentem ou não o seu trabalho valorizado, uma destas mulheres perguntou-me se tinha visto, no dia anterior, a reportagem na televisão sobre a morte do criador francês Hubert de Givenchy. Respondi que não. Descreveu-me então que tinham aparecido umas imagens de um desfile onde o criador aparecia no fim com umas senhoras de bata branca ${ }^{22}$ : "Penso que eram as costureiras. Eu não sei, mas acho que eram as costureiras. $\mathrm{E}$ aqui quem é que aparece? $\mathrm{O}$ estilista? $\mathrm{E}$ quem fez o sapato? $\mathrm{E}$ quem coseu?" E nesse momento, a distância entre uma passarela de uma qualquer capital da moda e os poucos metros quadrados de trabalho desta gaspeadeira ficou clara à minha frente.

\section{BiBLIOGRAFIA}

APICCAPS (ed.). 1994. Plano estratégico para a indústria do calçado. Porto: APICCAPS. Disponível em <http://www.apiccaps.pt/publications/plano-estrategico/116.html . APICCAPS (ed.). 2013. Footure 2020. Plano Estratégico-Cluster do Calçado. Porto: APICCAPS. Disponível em <http:/www.apiccaps.pt/publications/plano-estrategico/116.html>.

22 As "senhoras de bata branca" que surgem no final de um desfile junto com Hubert de Givenchy são as premières d'atelier. Importa referir que as premières d'atelier não são as maquinistas que costuram as peças, mas sim modelistas que trabalham diretamente com os esboços dos criadores/designers, traduzindo os desenhos em toiles (ou moldes planos), e que são responsáveis por seguir todos os passos da realização das peças. Logo, na hierarquia de um atelier, estão acima das costureiras. No entanto, o que aqui se quer fazer notar é como para esta gaspeadeira a imagem da bata branca associa-se aos trabalhos do fazer, levando a que tenha estabelecido um paralelismo entre o seu trabalho de fazer sapatos e o trabalho das "senhoras de bata branca", em jeito de identificação. 
APICCAPS (ed.). 2018. Facts $\xi^{\circ}$ Numbers. Porto: APICCAPS. Disponível em <http://www. apiccaps.pt/publications/facts--numbers/126.html>.

Bendix, Regina. 2015. "Patronage and Preservation: Heritage Paradigms and their impact on supporting 'Good Culture”. Pp.219-234 em Between Imagined Communities and Communities of Practice. Participation, Territory and the Making of Heritage, editado por Nicolas Adell, Regina Bendix, Chiara Bortolotto, and Markus Tauschek. Universitätsverlag Göttingen.

Boltanski, Luc, and Ève Chiapello. 2009 (1999). O novo espirito do capitalismo. Tradução Ivone C. Benedetti. São Paulo: Martins Fontes.

Boltanski, Luc, and Arnaud Esquerre. 2017. Enrichissement. Une critique de la Marchandise. Paris: Gallimard.

Bourdieu, Pierre. 2006 (1979). A Distinção. Crítica Social do Julgamento. Porto Alegre-São Paulo: Zouk/EDUSP.

DeNicola, Alicia Ory, and Clare M. Wilkinson-Weber. 2016. "Introduction. Taking Stock of Craft in Anthropology". Pp. 1-16 em Critical Craft. Technology, Globalization, and Capitalism, editado por Alicia Ory DeNicola, and Clare M. Wilkinson-Weber. LondonNew York: Bloomsbury.

Estanque, Elísio. 1999. Classe e comunidade num contexto em mudança: práticas e subjectividades de uma classe em recomposição. O caso do operariado do calçado em $S$. João da Madeira. Dissertação de Doutoramento. Coimbra: Faculdade de Economia da Universidade de Coimbra.

Harrison, Rodney. 2016. "World Heritage listing and the globalization of the endangerment sensibility". Pp. 195-217 em Endangerment, Biodiversity and Culture, editado por Fernando Vidal, and Nélia Dias. London-New York: Routledge.

Ingold, Tim. 2002 (2000). The Perception of the Environment. Essays on livelihood, dwelling and skill. London-NewYork: Routledge.

Lipovetsky, Gilles. 2012 (2003). "Luxo Eterno, Luxo Emocional”. Pp. 15-102 em O Luxo Eterno. Da idade do sagrado ao tempo das marcas, Gilles Lipovetsky, and Elyette Roux. Tradução Luís Filipe Sarmento. Lisboa: Edições 70.

Lipovetsky, Gilles, and Jean Serroy. 2013. L'esthétisation du monde. Vivre à l'âge du capitalism artiste. Paris: Gallimard.

Lofgren, Orvar. 1989. "The Nationalization of Culture". Journal of European Ethnology XIX: 5-25.

Mendes, Mónica Seabra. 2018. Quanto luxo cabe num par de sapatos?. Disponível em <http:// www.apiccaps.pt/news/quanto-luxo-cabe-num-par-de-sapatos/3240.html>.

Miller, Daniel. 2007. "Consumo como cultura material". Horizontes Antropológicos [Online], vol. 13, n. ${ }^{\circ} 28$. Disponível em <http://dx.doi.org/10.1590/S0104-71832007000200003>.

Ravelli, Quentin. 2017. “L'économie de l'enrichissement : nouveau stade du capitalisme ou illusion d'optique? Pistes de réflexion pour la critique de la marchandise". Revue de la régulation [Online], 22. Disponível em <http://journals.openedition.org/regulation/12454>.

Sennett, Richard. 1998. A Corrosão do Caráter: consequências pessoais do trabalho no novo capitalismo. Lisboa: Terramar.

Sennett, Richard. 2008. The Craftsman. New Haven-London: Yale University Press.

Silvano, Filomena. S.d. “Um antropólogo fazedor de objetos”. Pp. 16-20 em Fernando Brizio. Desenho Habitado.

Vidal, Fernando, and Nélia Dias (ed.). 2016. Endangerment, Biodiversity and Culture. LondonNew York: Routledge.

Xie, Philip. 2015. Industrial Heritage Tourism. Channel View Publications. 


\section{THE ART OF SHOEMAKING: WAYS OF MAKING AND PRESENTING IN THE PORTUGUESE FOOTWEAR INDUSTRY}

To survive and to adapt to global production and market dynamics, the Portuguese footwear industry is restructuring their production and business models, focusing on design and technological innovation, and the revival of artisanal production practices. Based on an ethnography of a shoe factory in Portugal, this article discusses the day-to-day of a industrial production sites that - in response to market dynamics that seek to revive the artisanal past to open up new economic opportunities - seek to reconcile the revival of traditional ways of making and modern modes of exhibition. Contrasting marketing discourses and production practices, the article analyzes the negotiation of the boundaries of concepts like "heritage" and "economy", exploring the artisanal knowledge and modern techniques of industrial production.

Keywords: industry, footwear, heritage, know-how, Portugal

Recebido em: 2018-07-31

Aceitado em: 2018-12-04 